\title{
The Second Annual Soviet-American Conference on Emergency Medical Care May 2-10, 1990
}

\section{Leningrad, USSR, May 2-3 \\ Tlibisi, Georgian SSR, May 4-6 \\ Moscow, USSR, May 7-10}

\section{Sponsors}

The Society for the International Advancement of Emergency Medical Care

The Ministry of Health, Union of Soviet Socialist Republics

The American College of Emergency Physicians, Maryland Chapter

\section{Host Institutes} Moscow

The N. V. Sklifosovosky Institute for Emergency Medicine,

The I. I. Djanelidze Emergency Medicine Research Institute, Leningrad

\section{Planning Committee}

Arno Vosk, MD

Teimuraz Gurchemilidze, MD

Theodore E. Harrison, MD

Alexey Ya Bagrov, MD

Louise B. Andrew, MD

Vladislav G. Teriaev, MD

Mikhail V. Grinev, MD
The changes taking place in Eastern Europe these days are keeping the world on the edge of its chair. With peace and democracy breaking out all over, it is a very heady time. This opening of borders and communications between East and West has given us a golden opportunity to establish relationships and dialogue with our colleagues in the Soviet Union. The second Soviet/American Conference on Emergency Medical Care (SACEMC II) is the vehicle with which we hope to start an ongoing tradition of professional exchange and communication between the emergency care providers of our countries.

American participants in this conference will have a front-row seat for, and perhaps even a supporting role in, the drama now being played out in the Soviet Union. The first SACEMC, with an American delegation led by Dr. Kathleen Handal, was such an inspiring success that it led to the formation of the Society for International Advancement of Emergency Medical Care (SIAEMC), an organization committed to the international exchange of professional literature and personnel. The United States and Soviet members of SIAEMC jointly planned and organized SACEMC II. This planning has culminated in a new, expanded conference schedule which we hope you will find exciting and interesting.

SACEMC III is now in the planning stages. Mark your calendars for next May.

—Theodore E. Harrison, MD 


\section{Tentative Itinerary (American Delegation)}

\section{April 29}

Meet in New York City at JFK International Airport, Depart for Frankfurt, FRG

April 30

Arrive in Frankfurt, FRG, Depart for Leningrad, USSR.

May 1

May Day in the USSR. Arrive in Leningrad

May 2

Conference at Djanelidze Institute.

May 3

Conference at Djanelidze Institute. Gala farewell dinner.

May 4

Fly to Tblisi, capital of Georgian SSR.

May 5

Tblisi Medical Institute and University

May 6

Emergency Medical Station Tours and Free Time

May 7

Fly to Moscow

May 8

Conference at Sklifosovosky Institute

May 9

Conference at Sklifosovosky Institute

May 10

Conference at Sklifosovosky Institute/Free Time. Gala farewell Dinner

May 11

Depart for United States

\section{2 and 3 May 1990 Leningrad \\ The I. I. Djanelidze Emergency Medicine Research Institute}

\section{Day 1 \\ Leningrad}

\section{0-Noon}

Presentation and Discussion of Papers

Prehospital Specialization for the Treatment of Traumatic Shock

Grinev MV

An Overview of The US EMS System Forbuss $R$
The Use of Prognostic Data to Determine Surgical Tactics in Multi-Trauma Shock

Grinev MV, Frolov GM, Kachansky YB, Desaev GM

Patterns and Mechanisms of Injury in Vehicular Trauma Koe FG

Predicting the Prognosis of Traumatic Shock Tsibin YN, Galtseva IV, Grinev MV, Shirokov VM

Does Alcohol Confer any Protective Advantages in Trauma? Blair PJ

The Use of the Extracorporeal Spleen in the Treatment of Traumatic Shock

Grinev MV, Tarekina MN, Tfybin YN, Frolov GM

The Role of Aeromedical Transportation in Disaster Health Care

Yancey $A H$

An Earthquake Happens: What Did We Learn? Blair PJ

Noon-1300

Lunch

1300-1500

Demonstrations of I. I. Djanelidze Critical Care Areas

1500-1700

Round-Table Discussion

Topic 1: Trauma Scoring Systems

Topic 2: Prehospital Care of Traumatic Shock

\section{Day 2}

Leningrad

\section{0-Noon}

Presentation and Discussion of Papers

Sensitivity and Specificity of a Rapid CK-MB Assay Green $G$, Fleetwood D, Hansen $K$, Chen $D$, Kelen $G$

Intravenous Laser Therapy in the Treatment of Ischemic Heart Disease

Maximov VA, Mazhara YP, Olesin AE, Skorodumova EA

Simplified Scheme for the Use of Automatic External Defibrillators by Lay Persons Briggs $N$

Endogenous Digoxin-Like Factor: Possible Emergency Implications Bagrov $A Y a$

Platelet Function in Thrombolytic Therapy Lewis B

Prehospital Thrombolysis in Acute Myocardial Infarction Varshavsky SYu

Intensive Training for Non-Physician Emergency Personnel Fowler $R$

The Intraosseous Infusion Technique Totten VM 


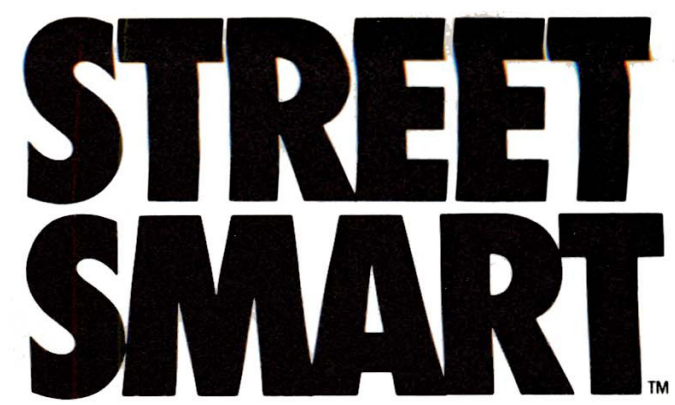

Optional built-in noninuasive pacemaker, Code Summary critical event recond, FAST-PATCH® adapter for bands-off defibrillation, compatible urith LIFEPAK 5 Battery Paks

Street smart for the EMS envinonment.

The new LIFEPAK 10 defibrillator/monitor is built in the rugged tradition of all LIFEPAK products.

Tough, sure, reliable. Giving you the confidence you need when you're out on the streets.

NEW! THE LIFEPAK 10 DEFIBRILLATOR/MONITOR

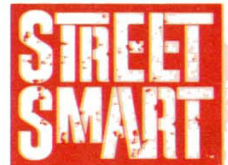


Noon-1300

Lunch

1300-1500

Demonstration of Leningrad Dispatch Center

1500-1700

Round-Table Discussions

Topic 1: Antiarrhythmic Drugs

Topic 2: Prehospital Thrombolytic Therapy

\section{7, 8, 9, 10 May 1990 Moscow The N. V. Sklifosovosky Institute for Emergency Medicine}

\section{Day 1 \\ Moscow}

\section{0-Noon}

Presentation and Discussion of Papers

\section{Overview of US EMS System}

Forbuss $R$

Development of an EMS Quality Control System in the USSR Teriaev VG, Stazhadze LL, Kostomarova LG, OleynikVA, Nikulin $B I, B u k T N$, Chervochkin EN

A Simplified Scheme for the Use of Automatic External Defibrillators by Lay Persons

Briggs $N$

Specialization of Prehospital Emergency Services

Shmatov AV, Stazhadze LL, Kostomarova LG, Elkis JS, Chervochkin EN, Vdovina $G$

Sensitivity and Specificity of a Rapid CK-MB Assay Green $G$, Fleetwood D, Hansen K, Chen D, Kelen G

The Role of Hepatic Injury in Death Following Multipee Trauma Vadimorava ES

Patterns and Mechanisms of Injury in Vehicular Trauma Koe FG

\section{Noon-1300}

Lunch

1300-1500

Demonstration of the Sklifosovosky Critical Care Areas

1500-1700

Round-Table Discussions
Topic 1: Specialty Ambulances

Topic 2: Prehospital Quality Control

\section{Day 2 \\ Moscow}

\section{0-Noon}

Presentation and Discussion of Papers

An Earthquake Happens: What Did We Learn? Blair PJ

Logistics of Fluid Resuscitation During Mass Casualty Situations Khbapov BP, Olvenik BA

The Role of Aeromedical Transportation in Disaster Health Care

Yancey $A H$

Organization of Temporary EMS Systems During the Armenian Disaster

Teriaev VG, Gazetov B

Does Alcohol Confer Any Protective Advantages in Trauma? Blair PJ

Platelet Function in Thrombolytic Therapy Lewis $B$

Intensive Training for Non-Physician Emergency Personnel Fowler $R$

Noon-1300

Lunch

1300-1500

Demonstration of Moscow Ambulance Dispatch Center and Specialty Ambulances

$1500-1700$

Round-Table Discussions

Topic 1: Disaster Equipment and Supply Logistics

Topic 2: Disaster Transportation

\section{Day 3 \\ Moscow}

0800-Noon

Polyclinic Tour and Demonstration of Sklifosovosky Institute 


\section{Prehospital Specialization for the Treatment of Traumatic Shock \\ Grinev $M V$}

The organization of prehospital medical care and development of specialized trauma centers has caused a significant decrease in major trauma mortality. According to Baxt and Moody (1987) prehospital treatment of these patients resulted in stabilization of the vital functions in $98 \%$ of the injured. In 1983, Tscherne reported that initiation of treatment within the first 22 minutes of severe trauma reduced mortality from $50 \%$ to $39 \%$.

We retrospectively analyzed the case histories of 2,195 trauma victims with shock who were admitted to the Djanelidze Institute in Leningrad. Seventy-three percent had multiple traumatic injuries. Prehospital care was provided either by specially trained ambulance teams $(66.2 \%$ of victims) or by regular ambulance teams $(32.9 \%)$. Prehospital treatment included analgesia, immobilization, and fluid resuscitation in $59.7 \%$ of cases. In 18 patients with grade III shock, vasopressor agents were used. Three cases of cardiac arrest were successfully resuscitated.

The results of the specialized and regular ambulance teams were compared. Overall, mortality was $20.5 \%$ (predicted mortality $27.3 \%$ ). In victims treated by the specialized ambulance teams, mortality was $21.9 \%$ (predicted mortality $27.3 \%$ ), but at the same time the mortality in the victims treated by the regular ambulance teams was $18.7 \%$ (predicted 24.8\%).

We conclude that specialization of ambulance teams does not improve outcome for victims with multiple traumatic injuries.

\section{An Overview of the United States Emergency Medical Services Systems \\ Forbuss $R$}

This paper offers an overview of ambulance services in the United States and their present role of providing prehospital care and transportation. Even though most ambulance services are not owned or directly controlled by hospitals or physicians, hospital-based, emergency physicians provide support and supervision through the use of telemetry and radio communication and through the development of prehospital medical protocols.

Ambulance services in the United States are generally established at two levels-Basic Life Support (BLS) and Advanced Life Support (ALS). Virtually all of the major cities now have advanced life support ambulance services

Ambulance deployment strategies can result in significant reductions in mortality. Computer modeling of ambulance call demand can predict where and when ambulances are needed. The resulting improvement in ambulance response has been shown to improve survival to hospital discharge from $4 \%$ (in systems with poor response times that function at a basic level to $12-16 \%$ (in systems with rapid response and ALS capability). 


\section{The Use of Prognostic Data to Determine Surgi- cal Tactics in Multitrauma Shock}

Grinev MV, Frolov GM, Kashansky YuB, Besaev GM, Tsibin YuN

Since 1975 , we have based our treatment of traumatic shock on the prognostic index developed by Tsibin and Galtseva which uses the condition of the victim and an estimation of the gravity of the injuries to predict outcome and duration of shock. In the present study we used this quantitative method to select groups of patients with equal clinical acuity and predicted outcome. We classified 1,350 patients into three groups.

1. Favorable prognosis - these patients were deemed stable enough to undergo full-scale surgery including osteosynthesis, reconstructive and plastic surgery operations, and reimplantation of limbs.

2. Doubtful prognosis-these patients were not thought stable enough for major surgery and so were treated mainly by nonoperative methods. External fixation was used for musculoskeletal injuries. No plastic or reimplantation operations were performed.

3. Unfavorable prognosis-these patients were too unstable to undergo any kind of surgery. They were treated conservatively except for the occasional necessary amputation or wound revision for hemostasis.

Fifty-five percent of the victims were determined to have a favorable prognosis, six percent had a doubtful prognosis, and 39 percent had an unfavorable prognosis. Therefore, some $61 \%$ of patients with traumatic shock were candidates for surgical repairs of some extent. Using these data we were able to increase our surgical activity from $12 \%$ to $39 \%$ without raising either total mortality $(29-30 \%)$ or postoperative mortality (12-10\%). The mortality in the operated favorable prognosis group was almost half that of the nonoperatively treated unfavorable prognosis group $(7.7 \%$ vs $13.3 \%$ ).

Thus, using prognostic data to determine the extent of surgical intervention helped more than half the victims of multi-trauma shock to get needed surgery performed within the first 48 hours without increasing the death rate and with improved results.

\section{Patterns and Mechanisms of Injury in Vehicular Trauma \\ Koe F}

In the United States, trauma is the leading cause of death up to age 44 years and is responsible for more deaths in the oneto 14-year age group than all other diseases combined. Motor vehicle accidents account for the largest share of trauma deaths. In 1985 , about 50,000 people were killed in crashes. For every death from trauma, there were two victims who sustained permanent disabilities.

The process of assessing a motor vehicular accident and determining what injuries might have resulted from the forces and motions involved is addressed by the study of impact biomechanics and occupant cinematics. The information presented comes from a comprehensive search of the literature and will touch upon methods and results of studies which involved a variety of professionals such as trauma and emergency physicians, pathologists, public health officials, automotive engineers, and researchers worldwide. Acceleration and compressive forces produce predictable injury patterns in each of the following types of motor vehicular accidents: head-on or frontal impact; rear impact; lateral or side impact; rotational impact; and rollover.

Awareness of the various mechanisms of injury in vehicular crashes enhances the assessment skills of the health care provider when he or she is confronted with a crash victim. Thus, it is likely that the prehospital emergency provider will triage the crash victim more accurately to the most appropriate facility. The emergentologist and traumatologist will command a heightened index of suspicion which will in turn lead to a more prompt working diagnosis resulting in the earlier initiation of life-saving and resuscitative measures. Awareness of preventable injuries hopefully will lead public officials, safety design automotive experts, and other concerned entities toward a safer motor vehicle. 


\section{LifeDefense Plus from Matrx The New Standard in Defibrillator/Monitor/Pacers}

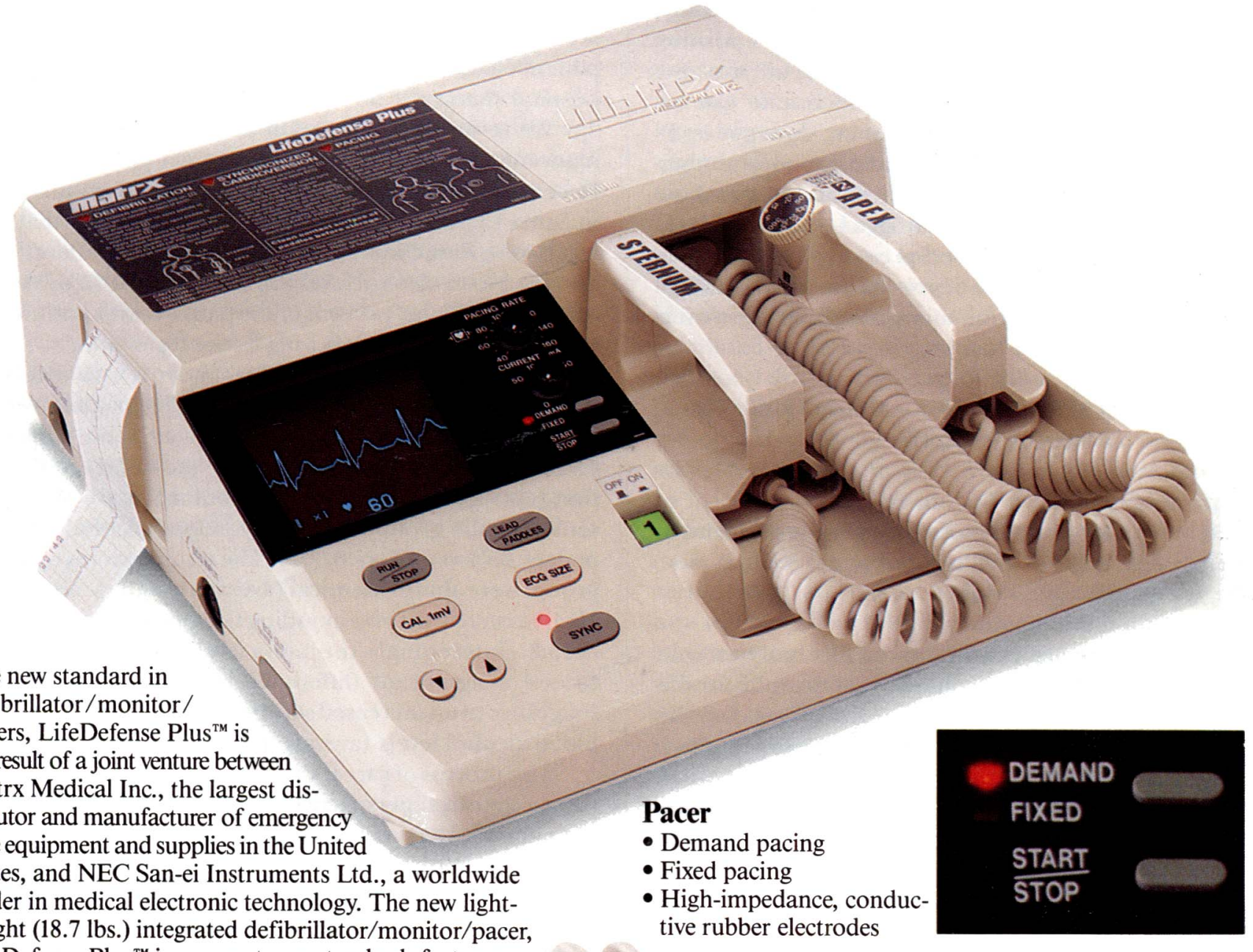

The new standard in defibrillator/monitor/ pacers, LifeDefense Plus ${ }^{\mathrm{TM}}$ is the result of a joint venture between Matrx Medical Inc., the largest distributor and manufacturer of emergency care equipment and supplies in the United States, and NEC San-ei Instruments Ltd., a worldwide leader in medical electronic technology. The new lightweight (18.7 lbs.) integrated defibrillator/monitor/pacer, LifeDefense Plus ${ }^{\mathrm{TM}}$ incorporates as standard, features that other units offer only as options.

\section{Defibrillator}

- Impedance indicator on paddle

- Energy setting on paddle

- Remote defibrillation

- Synchronized cardioversion

- Automatic recording of defibrillation event

- Pediatric paddle adapters

\section{Monitor}

- Large 7 sq. in. Sony ${ }^{\star}$ CRT screen

- Direct monitoring from ECG electrodes, paddles, or defibrillation electrodes

- Audio/visual message system

- Real/delay recording modes

- Annotated messages on Z-fold thermal paper
Battery support/accessories

- High-capacity 2.2 amp hour NiCad battery

- Multiple-function battery support system

- Full complement of quality Matrx accessories

For more information and a demonstration of LifeDefense Plus ${ }^{\mathrm{TM}}$, the new standard in emergency cardiac care, call Matrx at 1-800-845-3550.

\section{IIARE MEDICAL INC.}

Corporate Headquarters/Technical Information Matrx Medical Inc., 145 Mid County Drive Orchard Park, NY 14127

U.S. (716) 662-6650 (800) 847-1000

Distribution (800) 845-3550

Canada (800) 876-2879

United Kingdom (0252) 621442 


\section{Predicting the Prognosis of Traumatic Shock Tsibin YuN, Galtseva IV, Grinev MV, Shirokov DM}

We present our experience in the development of algorithms for the prediction of the prognosis in traumatic shock. Our formal $\pm \mathrm{T}$-index predicts the expected continuing duration of shock or the time until death. A positive value for the index indicates that the patient will live and gives the number of hours that the shock state can be expected to continue before stabilization. A negative Tindex predicts that the patient will die and gives the number of hours expected to death. The algorithms are based on simple anatomical and functional signs-trauma score, pulse rate, age, and systolic blood pressure. The formulas were determined by multiple regression analysis. the formula for prognostic determination of admission to the hospital is:

$$
\begin{aligned}
& 1 / \mathrm{T}=\quad 0.317-0.0039 \bullet \mathrm{K}+0.00017 \bullet \mathrm{BP} \bullet \mathrm{K} \\
& -0.0026 \bullet \mathrm{P} \bullet \mathrm{A} / \mathrm{BP}
\end{aligned}
$$

Testing of these algorithms showed that real outcome coincided with predicted outcome $97 \%$ of the time for the prehospital algorithm and $85-90 \%$ of the time for the hospital admission algorithm. A further algorithm predicting fluid resuscitation requirements has been developed from this experience. These results show that traumatic shock can be successfully described by computer simulation.

\section{Does Alcohol Confer Any Protective Advantages in Trauma? Blair PJ}

Popular belief asserts that alcohol consumption increases the incidence but decreases the severity of traumatic injury. We studied the relationships between blood alcohol level, patient characteristics, severity of injury, length of stay, and hospital charges.

We reviewed the charts of all patients sustaining traumatic injury in Santa Clara County from 1 January 1988 to 31 December 1988 who were triaged to a Level 1 trauma center in Santa Clara County ( $n=3712)$. Detectable blood-alcohol levels were found in $24 \%$ of this cohort ( 886 patients). The average blood alcohol level was $0.2 \mathrm{mg} \%$, with a peak value of $0.9 \mathrm{mg} \%$. Eighty percent of the patients with positive tests had levels greater than $0.1 \mathrm{mg} \%$, the legal limit.

Comparing the group of 886 patients with detectable blood alcohol levels to the group of 2,826 patients with no detectable blood alcohol demonstrated some important relationships. The two groups have the same age distribution (average age $=29.1$ vs 29.3 ), but males are over-represented in the group with positive blood alcohol levels (\% males $=85 \%$ vs $64 \%, p<0.005)$. The trauma scores of the two groups were almost identical (average trauma score $=10.6 \mathrm{vs}$ 10.4 ), as were the corresponding Glasgow coma scores (12.9 vs 13.2). Interestingly, the injury severity score (ISS) demonstrated a significant difference between the two groups suggestive of an increased severity in the group with positive blood alcohol levels (average ISS $=12.3$ vs $11.4, \mathrm{p}<0.005$ ).

The process of care for the two groups appeared similar from a statistical perspective. Total length of stay was about the same ( 3.7 days vs 3.4 days), as was average length of stay in the ICU ( 0.9 days vs 0.9 days). Unexpectedly, however, the average hospital charge was $27 \%$ higher in the group with positive blood alcohol levels $(\$ 5,600$ vs $\$ 4,400$ [US $\$$ ], $\mathrm{p}<0.005)$. Clinical outcomes remained comparable, as measured by similar survival rates (95\% vs $96 \%$ ).

We conclude that alcohol consumption has a detrimental effect on the severity of traumatic injury independent of its effect on incidence. 


\section{The Use of Extracorporeal Spleen Hemoperfu- sion in the Treatment of Traumatic Shock}

Grinev MV, Tarelkina MN, Frolov GM, Tsibin YuN

We report our experience of 212 treatments in 86 patients using extracorporeal hemoperfusion of pig spleen to help treat severe traumatic shock and its complications. In this technique, a fresh, aseptically removed, pig spleen was perfused with heparin and saline and transported to the hospital. The spleen was then attached to the patient through a vein to vein shunt and the patient's blood circulated through the spleen with a roller pump. Treatments lasted 30 to 60 minutes.

The clinical effects observed were reduction in temperature and degree of encephalopathy. Laboratory investigation showed decline in "middle molecules," fibrinogen levels, leucocyte intoxication index, and the number of circulating immune complexes. Plasma creatinine remained constant. Thrombocytes actually increased in number by the second day.

Extracorporeal spleen hemoperfusion also was found to have effects on the immune system consisting of phagocytosis, increased chemokinesis, and increased chemotaxis.

\section{The Role of Aeromedical Transportation in Disaster Health Care \\ Yancey $A H$}

Unique aspects of aeromedical transportation exist that render it vital to the overall management of disaster emergencies. Valuable time can be saved in moving medical expertise and supplies into the disaster area as well as moving victims out of the hazardous area quickly and in large numbers to the institutions of definitive care. Frequently observed chaotic ground traffic situations at the disaster scene as well as environmental obstacles en route can be avoided. Large numbers of disaster victims can be more efficiently cared for en route by proportionately fewer health care personnel due to the concentrations of patients in one aircraft. Patients with similar injuries (i.e., burns) can be routed to and concentrated in specialized institutions that specialize in the care of these specific injuries. The possibility for execution of the foregoing should include the use of military troop-transport aircraft that are easily converted for patient transport. Also, military personnel should be involved as they are already part of a highly organized structure that is more easily and swiftly mobilized than can most civilian organizations. The United States Air Force aeromedical evacuation policies and management structure will be reviewed briefly with attention directed toward additions and adaptations of and alterations in this system which will serve a global disaster response. Such a highly evolved system will require a governing body with global reach for purposes of coordination and management. The resources for such a system currently exist and are in operation but such an organization has yet to be formed. 


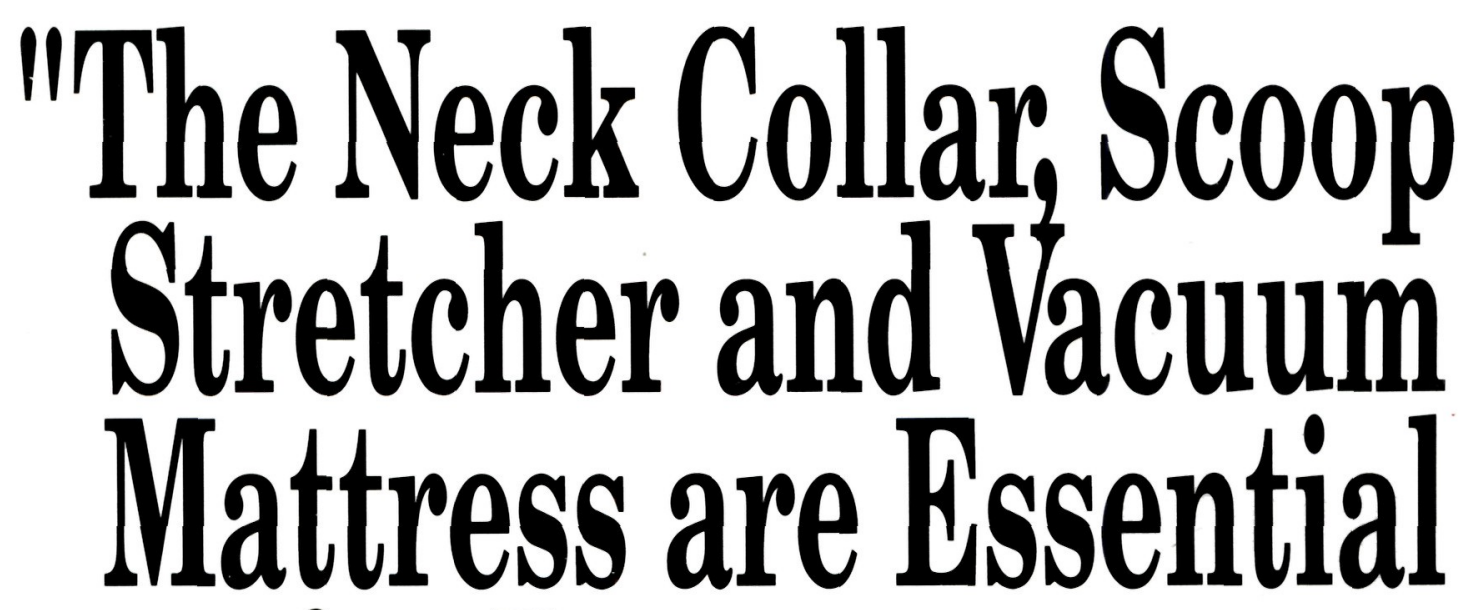

\section{for Rescue."}

\section{EVAC-U-SPLINT ${ }^{\circledR}$}

\section{The Complete Immobilization System}

E

VAC-U-SPLINT is an internationally recognized, orthopedic vacuum immobilization system. The

EVAC-U-SPLINT System is designed to provide emergency medical services personnel with the flexibility needed in meeting everyday, often difficult, field situations.

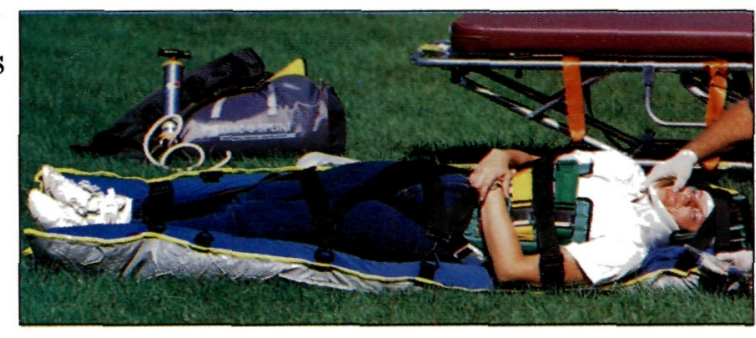

The EVAC-U-SPLINT System, in addition to its extremity splints, features a unique mattress. The EVAC-U-SPLINT Mattress provides patient immobilization by combining vacuum technology with conventional rigid supports that custom fit the patient with each application.

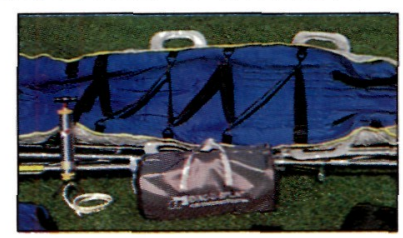

The EVAC-U-SPLINT System contours, cradles, and immobilizes the patient in comfort and safety from the scene throughout definitive care.

EVAC-U-SPLINT Mattress patent pending

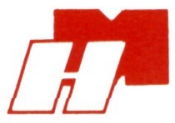

\section{HARTWELL MEDICAL}

INNOVATION AND EXCELLENCE IN MEDICAL PRODUCTS

1857 Diamond Street, San Marcos, CA 92069

For Customer Assistance outside California 800 MED 5900 (619) 471-6400 FAX (619) 471-6969

*Schou J, Jerger M.: "Technical Rescue in Spinal Injury." Emergency and Disaster Medicine. Xiaohong S., Moles M. (Eds). Beijing International Academic Publishers, 1989. 
PREHOSPITAL and DISASTER MEDICINE

\author{
A quarterly \\ peer-reviewed \\ scientific journal \\ for physicians, \\ nurses, paramedics, \\ instructors, \\ administrators \\ and researchers
}

The official journal of:

The National

Association of EMS Physicians

The World Association for Emergency and Disaster Medicine

\section{In Association with the Acute Care Foundation}

\section{JEMS \\ Journal of Emergency Medical Services}

$J E M S$ is the monthly professional trade journal for the emergency medical services industry.

Whether patient care or administration is your focus, JEMS provides you with the news and information you need to stay current with the field.

For nearly ten years $J E M S$ has been serving the needs of EMTs, paramedics and their instructors and supervisors.

Yes! Please enter my subscription to PDM for:

One year: $\square$ \$78 Institutional $\square$ \$48 Individual $\square$ \$35 Resident/In Training $\square$ \$35EMT, Pararaedic. RN Twavear: $\square$ \$148 Institutional $\square$ \$88 Individual $\square$ \$65 Resident/In Training $\square \$ 65$ EMT. Paramedic, RN NOTE: "Institutional" defines multiple reader subscriptions, including libraries, haspitals. government agencies, and all pritate organizations. Indicidual subseriptions must be paid by inditiduals.

Name/Institution

Address

City
$\square$ Bill me
$\square$ Charge my:
$\square$ VISA
$\square$ MasterCard
Exp. Date

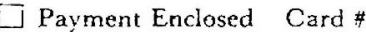
For Canadian subscriptions, Signature Date add $\$ 11$
Make checks payable to: PDM. P.O. Box 1026, Solana Beach, CA 92075
Occupation:
ᄃ Phosician
$\exists$ Vurse
$\square$ ENeT. Paramedic
- Administrator.'Supv. Purch Agers
Disaster Civil Defenst Planner
$\sqsupset$ oiher
Employment Location:
$\square$ Hospital
Fire Departrient
Fimbulanue Service
$\square$ Regional. State :Federal Agener
Endusery

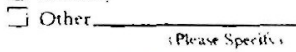

\section{Prehospital and Disaster Medicine}

Zip

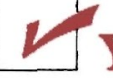

Yes! Please enter my subscription to PDM for:

One year: $\square$ \$78 Institutional $\square$ \$48 Individual $\square$ \$35 Resident/In Training $\square$ \$35 EMT, Paramedic, RX Two year: $\square$ \$148 Institutional $\square$ \$88 Individual $\square$ \$65 Resident/In Training $\square$ \$65 EMT. Paramedic, R.N NOTE: "Institutianal" defines multiple reader subscriptions, including thbraries. hospitals, government apencies, and all private organizations. Indit idual subscriptions must be paid by indiciduals

Name/Institution

Address

City State Zip

$\square$ Bill me $\square$ Charge my: $\square$ VISA $\square$ MasterCard Exp. Date

$\square$ Payment Enclosed Card $\#$

For Canadian subscriptions, Signature Date

Hake checks payable to: PDM, P.O. Box 1026, Solana Beach. CA 92075

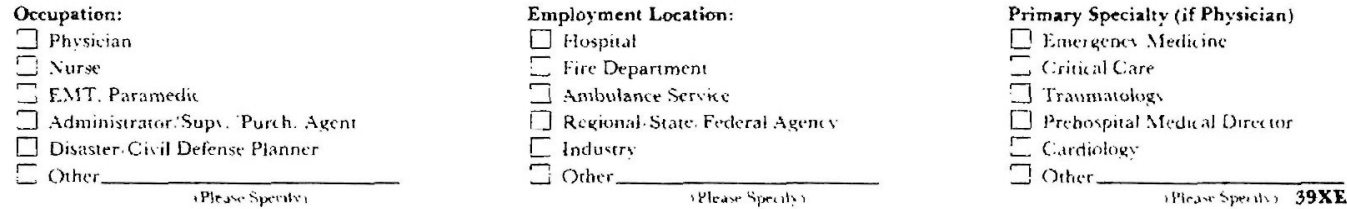

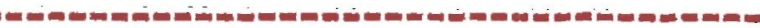

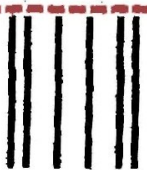

\section{BUSINESS REPLY MAIL FIRST CLASS PERMIT NO. 6 SOLANA BEACH, CA}

POSTAGE WILL BE PAID BY ADDRESSEE

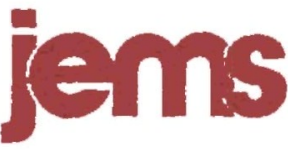

P.O. Box 27966

San Diego, CA 92128-9959
NO POSTAGE NECESSARY

IF MAILED

IN THE UNITED STATES 


\title{
Subscription and Business Information
}

\author{
for the Readers of
}

Prehospital and Disaster Medicine

\section{SUBSCRIPTION PRICES}

\section{One-year \\ (4 issues) \\ Two-year \\ (8 issues)}

Institutional $\ldots \ldots \ldots \ldots \ldots \ldots \ldots \$ 78 \ldots \ldots \ldots \$ 148$

Individual . . . . . . . . . . . . . . \$ $\$ 48 \ldots \ldots \ldots 8$

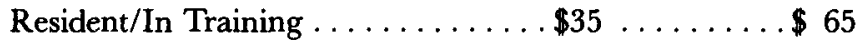

EMT/Paramedic/Nurse $\ldots \ldots \ldots \ldots \$ 35 \ldots \ldots \ldots \$ 65$

Note: "Institutional Subscribers" are defined as multiple reader subscribers and include public and private libraries, schools, hospitals and clinics; city, county, state, provincial and national government bureaus and departments; and all commercial and private institutions and organizations.

Individual subscriptions and all student-rate subscriptions must be in the name of, billed to, and paid by individuals. All studentrate requests must indicate training status and name of institution.

Send U.S. subscription orders to: Jems Publishing Company, PDM, P.O. Box 1026, Solana Beach, CA 92075; 619/481-1128; FAX: 619/481-2711.

\section{INTERNATIONAL SUBSCRIPTIONS}

Canadian subscribers add $\$ 10$ per year for postage and handling. Please include payment in U.S. funds.

For European subscriptions, contact: IOS, Van Diemenstraat 94, 1013 CN Amsterdam, Netherlands, FAX: + 3120226055.

For Japanese subscriptions, contact: IOS Japan Dept., Highway Developments Co. Ltd., 1st Golden Bldg., 8-2-9 Ginza, TokyoChuoku, Japan 104, FAX: +81 35728672 .

All other international subscription orders should be directed to: Jems Publishing Company, P.O. Box 1026, Solana Beach, CA 92075; telephone: 619/481-1128; FAX: 619/481-2711. All other international subscribers add $\$ 20$ per year.

\section{CHANGE OF ADDRESS \& MISSING ISSUES}

Please let your subscription representative know as soon as possible when you plan to move. We need four to six weeks advance notice for uninterrupted service. Send us your 1) current mailing label (with old address), 2) your new address and 3) effective date of change. If you did not receive an issue, let us know within three months of cover date.

If you have other questions about your subscription, please address them to: Customer Service, Jems Publishing Company, P.O. Box 1026, Solana Beach, CA 92075.

\section{EDITORIAL INFORMATION}

Please address all manuscript and editorial inquiries and comments to: Marvin L. Birnbaum, Editor, Prehospital and Disaster Medicine, 1552 University Ave., Rm. 434, Madison, WI 53705; 608/263-2069 or 608/263-7094; FAX: 608/263-2069.

\section{ASSOCIATION CONTACTS}

National Association of Emergency Medical Services Physicians, Executive and National Resource Center, 230 McKee Place, Suite 500, Pittsburgh, PA 15213; 1-800/228-3677.

World Association for Emergency and Disaster Medicine, Dr. Peter J.F. Baskett, President, Dept. of Anaesthesia, Frenchay Hospital, Bristol BS 16 1LE, United Kingdom.

Acute Care Foundation, P.O. Box 280173, Tampa, FL, 33682; 813/687-1574.

National Association of State EMS Directors, Council of State Governments, P.O. Box 11910, Lexington, KY 40578-1910; 606/252-2291.

\section{JEMS - Your Monthly Guide to EMS}

$J E M S$ was created ten years ago with one goal in mind: to provide the top men and women of EMS with a monthly journal that would serve them as well as they serve their patients. Publisher Jim Page has been involved in EMS for over 30 years as a rescuer, administrator, attorney, lecturer and writer. He designed a journal that would feature lively writing and graphics to match the dynamic growth of the EMS industry.

\section{You'll find in JEMS:}

- Monthly case studies of actual prehospital calls for CEU credit for EMTs and paramedics.

- "Tricks of the Trade" to enhance your patient care skills.

- Up-to-date news on the people and events that affect your job.

- A yearly salary of all EMS personnel-how does your department compare?
- Comprehensive information resources on all aspects of EMS

- Annual buyer's guide with the most complete and accurate listing of products, services, manufacturers and distributors.

- Essays and opinion on the issues you face everyday on the street, in the classroom and in your organization.
- Photographs and artwork that explain and entertain.

- Interpretive reports on the current research.

- Regular columns on pediatric care, EKG interpretation, clinical questions and answers, new books and new products.

- Regular columns on quality assurance, instructor training, the public/private interface and legal issues.

To subscribe, please fill out the attached card.

If missing, please send a check for $\$ 19.97$ for a year's subscription (12 issues) to: 


\section{An Earthquake Happens: What Did We Learn? Blair PJ}

Natural disasters represent infrequent events of enormous magnitude. We studied the response of the Emergency Health Care System (EHCS) to the recent Loma PietraSan Francisco Earthquake (magnitude 7.1 on the Richter Scale).

We reviewed the performance of all hospitals in the four county region affected by the earthquake (Santa Clara, Santa Cruz, San Mateo, and San Francisco). Such hospitals had pre-planned disaster protocols for managing mass casualties. However, these plans exclusively focused on disasters occurring outside of the hospital. This approach assumed the integrity of the hospital's structure, function, and personnel. The fifteen seconds of intense vibration showed that hospitals are not immune to such devastatlon. Many hospitals sustained ruptured gas mains, shattered glass, leaking pipes, and falling walls. Heating, lights, communications, plumbing, and elevators all failed to function in at least one hospital. Crucial health care workers were compelled to go home in response to family obligations. The overwhelmed Emergency Medical Services (EMS) paramedic communication systems had significant difficulty adapting either to the increased community needs or to the decreased hospital capabilities. The public media provided the most effective means of mass communications

We conclude that hospitals are ill-prepared when natural disasters affect their structural integrity.

\section{Intravenous Laser Therapy in the Treatment of Ischemic Heart Disease}

Maximov VA, Mazhara YuP, Olesin AI, Skorodumova EA

During the last several years, it has been demonstrated that intravenous (IV) and intracardiac (IC) radiation of blood by a neon-helium laser may cause several beneficial effects in patients with ischemic heart disease, especially in the acute stages. These include: antiarrhyth mic and antifibrillatory activity; stimulation of tissue and humoral immune responses; enhancement of the microcirculation; and anticoagulant activity (Meshalkin and Sergievsky 1982, Kipshidze et al 1988). We report our experimental and clinical results suggesting the efficacy of this method.

Experiments were set up using rabbits, male cats, and mongrel dogs. The effects of low-energy $(6 \mathrm{~W}, 9 \mathrm{~J})$ laser IV radiation were studied. Compared to control animals, radiation produced a lowering of blood cholesterol level, anticoagulant action, and increased myocardial contractility. In experimental groups in which the arrhythmias were produced by barium chloride, stophanthin, or acute coronary ligation, the antiarrhythmic effect of IV laser radiation caused a reduction in frequency and duration of cardiac rhythm disturbances. In experimental myocardial infarction (MI), the laser treatment significantly decreased the size of infarction and lowered the serum concentration of products of membrane lipid peroxidation.

We studied 158 patients with ischemic heart disease, including 60 with acute myocardial infarction (MI). In all patients, the treatment inhibited platelet aggregation and lowered lipid peroxides. In patients without MI, there was a $75 \%$ decrease in SVT, A-Fib, and A-flutter. In patients with $\mathrm{MI}$, treatment lowered the risk of ventricular fibrilation (VFib) by 2.5 times, prevented LV failure and recurrent chest pain, and reduced PVCs by a factor of 1.5 . No complications or side effects were observed.

These data suggest the efficacy of IV radiation by neonhelium laser in ischemic heart disease. Further study of the biological effects of laser radiation should provide more definitive information about the basis of its therapeutic effects. 


\section{DOES YOUR COLLAR MEASURE UP TO STIFNECK? DOES IT HAVE AN...}



\section{ANSWER FOR NO-NECKS ...}

The recently introduced NO-NECK ${ }^{\mathrm{TM}}$ size enables you to properly fit those patients with extremely short necks who used to be a real problem. STIFNECK's broad range of fit has been expanded even further by the addition of a BABY NO-NECK ${ }^{\mathrm{TM}}$ model designed to fit children aged 1 to 4 years.
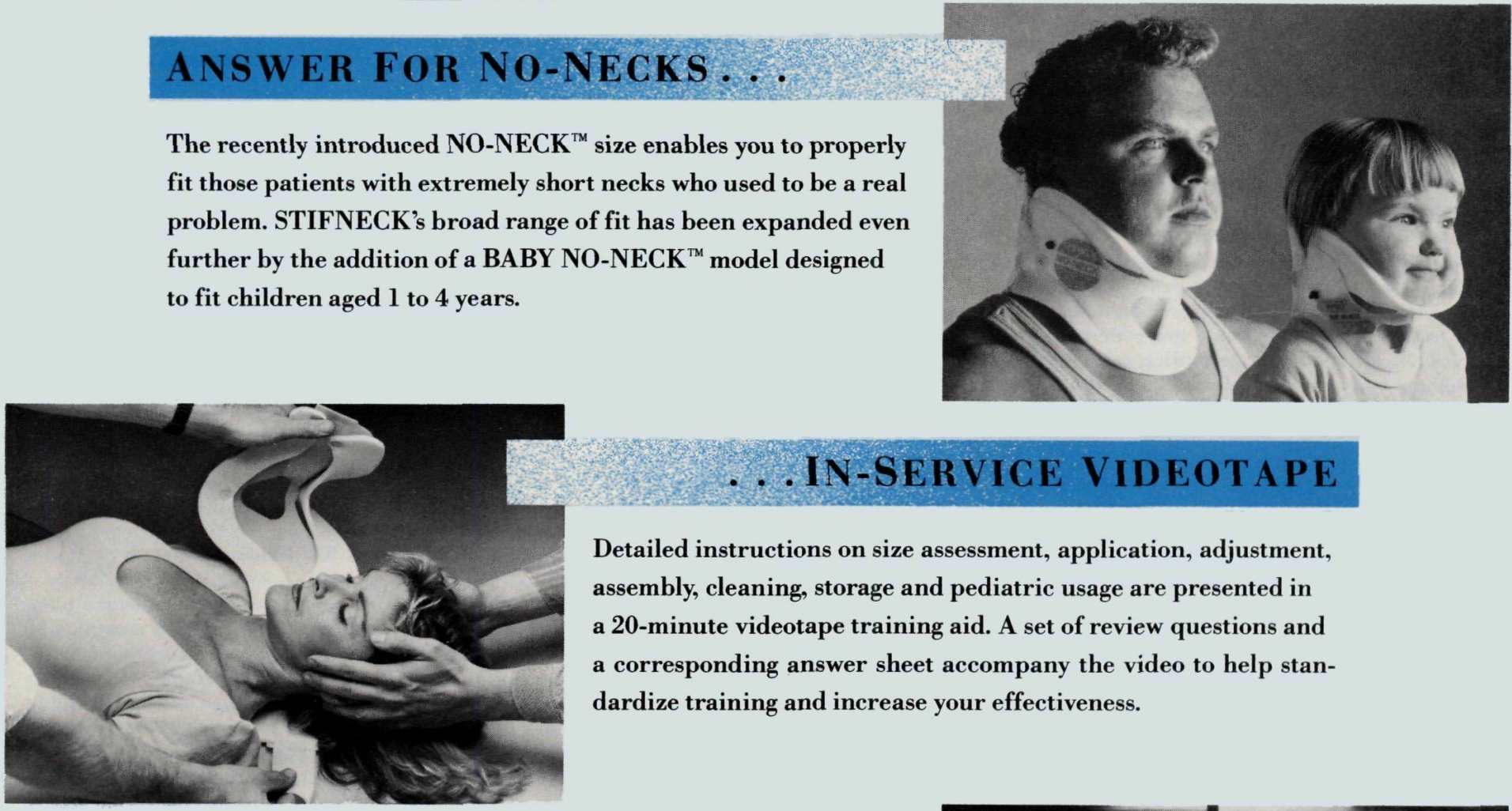

\section{.. IN-SERVICE VIDEOTAPE}

Detailed instructions on size assessment, application, adjustment, assembly, cleaning, storage and pediatric usage are presented in a 20-minute videotape training aid. A set of review questions and a corresponding answer sheet accompany the video to help standardize training and increase your effectiveness.

X-RAY DOCUMENTATION PACKET

You can feel confident when using STIFNECK ${ }^{\mathrm{TM}}$ as a series of radiographic studies have shown the collar to provide safe and effective immobilization of the cervical spine in the neutral position. In addition, comparative $\mathrm{X}$-ray studies have shown STIFNECK ${ }^{\mathrm{TM}}$ to provide a higher degree of immobilization than other cervical collars tested.

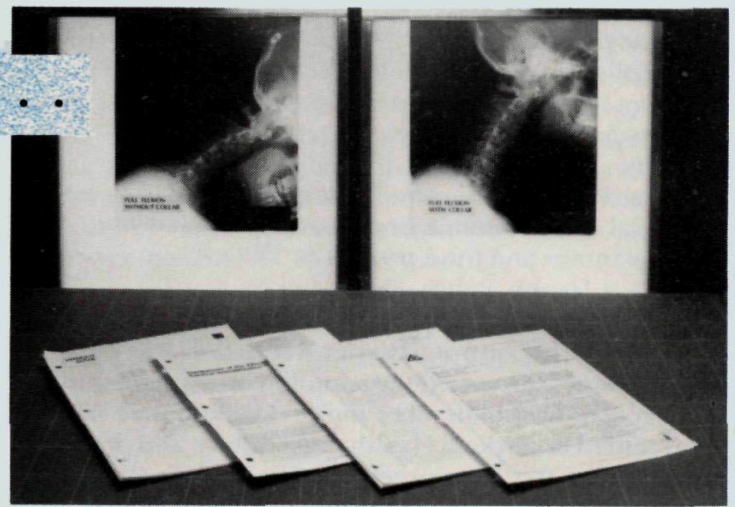

\section{DON'T \\ ICIPT SLIBSTITLTTES DEMAND THE BEST. BEST. .. STIFNECK.}




\section{Simplified Scheme for the Use of Automatic External Defibrillators by Lay Persons \\ Briggs $N$}

The 1986 American Heart Association (AHA) standards for Advanced Cardiac Life Support (ACLS) emphasized that the most important factor in successful conversion of patients in ventricular fibrillation (VF) was the speed at which defibrillation could be provided following the onset. The AHA standards recommend the use of both conventional defibrillators by personnel trained to recognize $\mathrm{VF}$ and automatic external defibrillators (AED) by lay persons.

The potential of the use of AEDs by lay persons both in industrial and public settings, and in the homes of high risk patients has been examined. Automatic external defibrillators are devices programmed to identify rhythms which meet a predetermined set of criteria such as VF. The device then delivers the appropriate level of electricity and reassesses the rhythm. Since the operator only is required to properly attach the device to the patient and operate an on/off switch, this device can be used in settings such as industry and public gatherings as well as in the homes of high-risk patients by persons with minimal training.

Several studies have investigated the results of placing AEDs in these settings for use by lay persons. However, problems have been identified which interfere with their proper use. Cummins et al (1985) found that the most difficult area of their protocol was the integration of CPR steps with the steps of using the AED.

To simplify the protocol for use by lay persons, it may be necessary to adopt a scheme similar to the ACLS algorithm for VF when a patient already is being monitored. In this protocol, CPR is not started before defibrillation if a monitor is available. The protocol directs that three shocks be given in sequence before CPR is started. The time necessary for the AED to be retrieved, attached to the patient, turned on, and the shock delivered is the factor determining the feasibility of dispensing with the CPR sequence prior to AED use. Moore at el (1987) determined a mean time of 4.1 minutes for completion of the entire cycle of AED use by trained lay persons. However, one cycle of CPR and the first shock could be delivered in about two minutes. If the initial cycle of CPR is deleted, it may be possible for the first shock to be delivered much more rapidly. Although no specific time limit has been identified during which application of defibrillation without prior CPR is as effective as (or more effective than) delaying defibrillation to deliver a cycle of CPR, it is possible that it will lie within the the time frame of successful AED use.

\section{Endogenous Digoxin-Like Factor: Possible Emergency Implications

\author{
Bagrov $A Y a$
}

Endogenous digoxin-like factor(s) (EDF) is an as yet unidentified circulating substance that plays an important role in water-electrolyte homeostasis and is involved in the pathogenesis of some forms of hypertension. Data have suggested a direct cardiac effect of EDF. Because of the sensitivity of ischemic mycardium to the arrhythmogenic action of the digitalis glygosides we hypothesize that EDF plays a role in the occurence of ventricular arrhythmias during acute myocardial infaction (AMI).

Our experiments in coronary-ligated male cats showed that the acute administration of antidigoxin antibodies (AA) caused a fivefold increase in the fibrillation threshold. In another experiment, we monitored the plasma concentration of digitalis and EDF in experimental AMI in Wistar rats. We observed a significant correlation between erythrocyte ATPase inhibition (indicative of digitalis/EDF activity) and ventricular arrhythmia incidence ( $r=-.84$, $\mathrm{p}<0.001$ ). Administration of AA increased enzyme activity and decreased the incidence of arrhythmias. In a study of 25 AMI patients during the first 24 hours we observed a marked increase in digitalis/EDF concentrations as compared to 18 healthy controls and 11 patients with progressive angina pectoris. There was a correlation between the erythrocyte ATPase activity and the plasma ATPase inhibitory potency in patients with AMI $(r=.65, p<0.001)$. This inhibitory activity was blocked by AA. Similarly, in 47 patients with AMI, we observed a 2.5-fold increase in plasma digoxin-like immunoreactivity compared with that of healthy and with unstable angina controls. High EDF levels remained elevated four to five days following AMI and these gradually decreased. Interestingly, in eight patients with AMI complicated by pulmonary edema EDF levels were significantly lower than even in healthy subjects.

These data indicate that besides its generally accepted natriuretic role, EDF is involved in "emergency" cardiac regulation and probably participates in the pathogenesis of ischemia-induced arrhythmias. Antidigoxin antibodies (AA) and other EDF antagonists may prove useful in the acute treatment or prevention of cardiac arrhythmias in AMI. 


\section{National Association \\ EMS Physicians}

\section{Platelet Function in Thrombolytic Therapy} Lewis $B$

The widespread use of thrombolytic therapy in the treatment of acute myocardial infarction has directed increased attention to the relationship between platelet activity and fibrinolysis. In vitro and animal studies show that platelet activity can delay reperfusion and mediate reocclusion. Limited but clinically useful information is available from human trials to suggest the adjunctive efficacy of antiplatelet therapy during thrombolysis. These data are presented in the context of current techniques of thrombolytic therapy.

\section{Intensive Training for Prehospital Non-Physi- cian Personnel}

Fowler $R L$

North American emergency medical services (EMS) systems are predicated upon the existence of a variably-trained, non-physician, medical provider. This type of provider was first trained formally following a national Congressional Act in 1973 that funded training throughout the United States.

Curricula for emergency medical technician (EMT) training programs have been variable in format, minimally coordinated across the United States, and available from numerous entities over the past 17 years. The Department of Transportation (DOT) has released curricula for both EMT-A (basic EMT) and the EMT-P (paramedic). Most states accept the DOT Programs as the basis for standards of training. The American Society for Testing Materials (ASTM) has established a voluntary standard accepting the DOT EMT-A program as a minimum standard for training the EMT.

Originated in 1982, the Basic Trauma Life Support (BTLS) program is a highly focused, intensive program designed to provide aggressive training in patient assessment and the management of the trauma victim. Studies before and after BTLS training indicate that the patient assessment skills of EMTs are subject to decay. Thus, it is necessary for constant assessment of the medical provider's skills and frequent provider retraining at appropriate intervals.

This paper discusses the history of non-physician, prehospital provider training, presents current studies of performance skills and retention, and offers suggestions for proper training, retraining, and future studies.

April - June, 1990

\section{Membership Information}

\section{Full Membership}

Full members shall be physicians who are actively engaged in the planning, supervision, teaching or clinical practice of prehospital emergency care. Full members shall enjoy all the privileges of the Association, including voting rights, committee membership, election of officers, conduction of business on behalf of the Association, and the right to advise and guide the Association in the conduct of its affairs.

$\$ 125.00 / y r * *$

\section{Organizational Membership}

Each organizational member is allowed up to five (5) physician representatives. Organizational members shall enjoy the same privileges as full members but are permitted only one vote. Application must be accompanied by curriculum vitaes of all five (5) physicians.

$\$ 500.00 / y r$ *

\section{Resident/Medical Student Membership}

Open to all residents/medical students interested in EMS. Application must be accompanied by a letter from residency program director or medical school dean verifying residency/student status and anticipated graduation date. Residents and medical students will enjoy all privileges of the Association as full members, however, only residents shall have the right to vote.

$\$ 50.00 / y r . *$

\section{Associate Membership}

Associate members shall be those persons who have demonstrated an interest in prehospital care and the aims of the Association through their writings, research, public pronouncements or activities. Associate members may be requested to sit on committees, to advise or to conduct research or investigations at the discretion of the Executive Committee. They shall have no right to vote, hold office or chair committees.

$\$ 50.00 / y r . *$

\section{For a membership application form write to:}

National Association of EMS Physicians EXECUTIVE AND NATIONAL RESOURCE CENTER 230 McKee Place, Suite 500 Pittsburgh, PA 15213

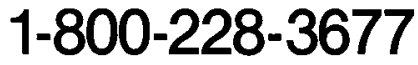

*All memberships include journal subscription. 


\section{On The Road}

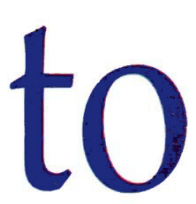

\section{Preconference Workshops}

National EMS Medical Director's

Course:

Wednesday, June 13 - Thursday,

June 14

Conference

of the

National

Association

of EMS

Physicians of the American College of Emergency Physicians \& the American College of Emergency
June 13-17,

1990 Westin

Galleria

Houston,

Texas
This is the National Association of 1 EMS Physicians, Florida Chapter Physicians' EMS Medical Director's Course. Recognized experts in the various aspects of prehospital care have developed an organized body of knowledge that each EMS Medical Director should possess to understand his or her role, responsibilities and available tools to properly supervise their EMS system. The student will have the opportunity to evaluate his/her system with consultation by the faculty. The following topics will be presented:

- Quality Assurance Programs

- Roots and Core Philosophy of EMS

- Employer/Employee Relations

- Demands of the Practice and Perspective of EMS

\section{Welcoming Address}

\section{Special Welcoming Reception and Opening Address \\ Thursday, June 14 \\ Michael Moles, MD \\ Chairman, 6th World Congress Hong Kong}

oming to America Terrorism and the Role of the

EMS System Manager

\section{Featured Presentations}

Monitoring Resuscitation: New Directions in Advanced Cardiac Life Support

Joseph Ornato, MD, Charles Brown, MD, \& Paul Pepe, MD

D rehospital \& Emergency

1 Department Use of End Tidal $\mathrm{CO}_{2}$

During Cardiac Arrest, Detecting

Downtime, Prehospital Clinical

Predictors of Outcome

Outside The City Limits, Rural and Wilderness EMS Care Workshops

What EMS Medical Standards Should Be Changed Outside the Urban Area, Stress Reduction And Advice For The Underpaid, Overworked Volunteer Medical Director, Triage, Transport \& Transfer Beyond Suburbia: Liability, Latitude \& Lives Lost

View From The Bench/A Review of EMS Malpractice Cases

Norman Dinerman, MD, A. Jack Ayres, JD, Carol Shanaberger, ID

Issues Facing EMS Providers Today Drs. Norman \& Henya Kagan

Psychological Testing Models for EMS Personnel

Trauma Center Closures \& Diversions: When There's no Room at The Inn

Compton Broders, MD, Lawrence Mottley, MD, William Koenig, MD, David Prentice, MD, Ronald Fischer, MD, Kenneth Mattox, MD, and lohn Ashworth

Atempted EMS Policies Across A The U.S., Academic

Consequences Behind The Scenes, The Economies Of Trauma As a Societal Issue

\section{Meeting The Special Needs of Children Within EMS}

Robert Luten, MD, Susan Fuchs, MD,

Peter Pons, MD, Arthur Funke, $M D$ 


\section{Featured Presentations}

Tsues and Controversies In Pediatric

IEMS, Practical Approaches To

Children In The Field, Airway

Management, IV And Intraosseous

Access

\section{Resuscitation \& Prehospital \\ Research}

Donald Yealy, MD, Peter Pons, MD,

Wes Warnke, EMT-P

TRB's and Consent In The

Prehospital Setting, Problems \&

Pitfalls In EMS Research, Design \&

Better Execution

Consensus Workshop on Medical

Supervision Control of First

Responders, EMT's and Volunteers

Bartholomew Tortella, MD

\section{Point-Counterpoint in EMS}

- Prehospital Pacing - Is It Worth It?

- When The Patient Or The Family

Doesn't Want To Go To The Trauma

Center, Should We Go Anyway?

- Deja Vu All Over Again - The Ultimate MAST Dual

- Prehospital IV Fluids: Are They Needed? New Data On Early Management of Uncontrolled Hemorrhage

\section{Hotel Information}

Westin Galleria, Galleria Mall, 5060 W. Alabama, Houston, Texas

Phone: (713) 960-8100

Rates: \$80/Single: \$90/Double \$110/Triple \& Quad \$250-350/1 \& 2 Bedroom Suites

The Westin is ideally located in the Galleria Mall complex. Here you can shop the world's most glamorous stores, see a show or browse though an art gallery.

ACCREDITATION: NAEMSP has applied for continuing education credits through the American College of Emergency Physicians, Family Physicians and CEU's for Nursing. Harmful On EMS

City

State

\section{Special Concurrent Sessions:}

\section{Meet The Specialist}

A sk The EMS Professor: Better

A ways to Write The Abstract \&

Present The Paper

- Ask The OB Specialist: Do's \& Don'ts of OB Care In The Field

- Ask The Neuro Specialist:

Prehospital Narcan, Thiamine \& D50W - Are They Needed Or

- Ask The EMS Pediatric Specialist: What Do You Really Need For Prehospital Toddler Care?

- Ask The Heart Specialist: The Future Of Prehospital MI Management. Thrombylysis, \& Its Technological \& Educational Impact

The Choreographer In The Crucible: Problem Solving In EMS

A sk The EMS Dinosaur: Surviving A The Ice Age -- Getting Cynical

Without Getting Out

\section{Yes, Please send me a Registration Packet for the Sixth Annual Conference of the National Association of EMS Physicians.}

Name

Specialty

Organization

Address Zip-Code

Please mail coupon to: Kathleen M. Stage, NAEMSP

230 McKee Place, Suite 500

Pittsburgh, PA 15213 


\section{The Intraosseous Infusion Technique Totten VM, Bielenstein J}

This paper describes the history and method of intraosseous infusion (IOI). Its indications, contraindications, complications, and use as a route for the administration of medications are reviewed. This technique permits rapid access to the vascular space in adults or children even in the presence of conditions which obliterate the peripheral veins. It has proven value in burn victims, patients in convulsions or in shock, and in the obese or severely edematous.

The intraosseous infusion technique requires little more than a steel needle, preferably one with a stylet, with which to penetrate the bony cortex. The use of sternal and tibial sites are discussed in depth. This paper provides step-by-step instructions on the establishment of access to the tibial bone marrow and discusses the special requirements associated with the use of the sternum. The steps in the technique are: 1) select and prepare the site; 2) local anesthetic (if time allows); 3) introduce the needle through the bony cortex with screwing, boring motion; 4) aspirate and flush the needle; and 5) connect intravenous (IV) fluids.

The intraosseous infusion technique has been shown to be relatively free of complications, even in unskilled hands. It permits much the same infusion of fluids and medications as does the IV route. Its use can be life-saving when peripheral venous cannulation can not be achieved rapidly.

Two cases are reviewed.

\section{Development of an EMS Quality Control Sys- tem in the USSR}

Teriaev VG, Stazhadze LL, Kostomarova LG, OleynikVA, Nikulin BI, Buk TN, Chervochkin EN

One of the important problems of Public Health Management is the quality assessment of medical care. The most universal measure of quality assessment is the effect of the activities of the health-care system activities on mortality, morbidity, etc. In practice, this can be accomplished for each medical facility by establishing indices of ultimate outcomes which reflect the quality criteria and are the control indicators and tools for quality assessment of medical care. Such indices should be established for each patient category (diagnosis-related group) depending on the type of medical facility and the stage of medical care delivery.

We developed a quality assessment system for EMS delivery within a region. The system passed though five developmental stages. The stages include the development of:

1. Standards of prehospital and hospital emergency medical care for various types of emergencies. The standards include all diagnostic, medical, organizational, and tactical measures required to ensure the established minimal level of care.

2. A criteria list reflecting the ultimate outcomes of prehospital and hospital EMS activities.

3. Normative meanings of outcome criteria for both the EMS activity as a whole and its subdivision's activities. The standard should exceed the current level by $5 \%$ but remain within the bounds of possibility of achievement with the effective use of resources, organization, diagnostic tests, and treatment.

4. A list of possible errors.

5. An assessment scale which includes both the assessment of each normative index and points depending on its functional value and the quantitative assessment of the degree of deviation from the normative meaning of each criterion.

Integral assessment of quality is the coefficient of achieving the planned outcome (ratio of the actual sum of points to the standard sum of points on the assessment scale). 


\section{Responding....to Your Changing Needs}

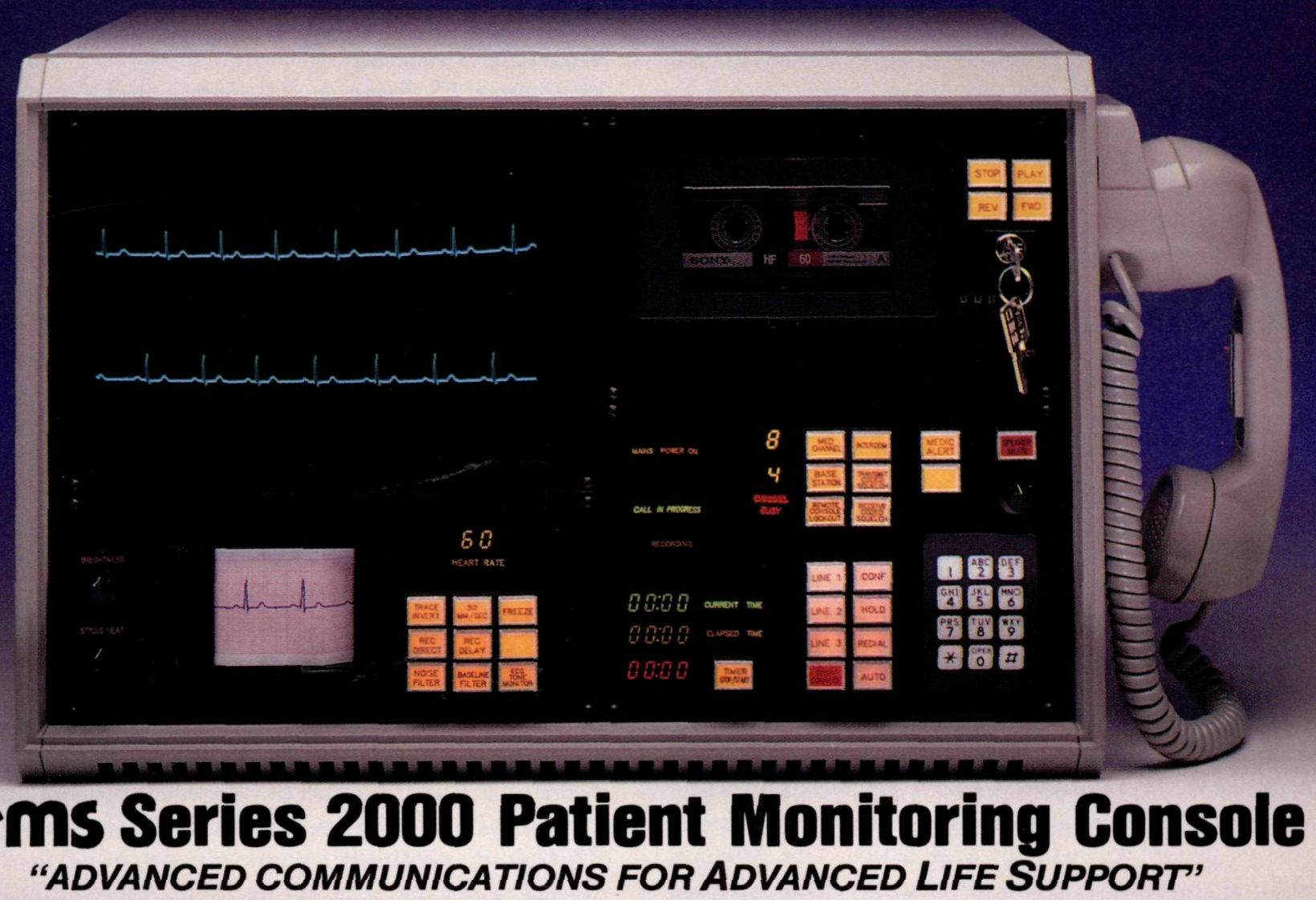

\section{Cost Containment-Cellular Telephone- Thrombolytic Agents...the ALS world is changing! \\ That's why you need the GEMS SERIES 2000 PMC.}

Designed specifically to keep pace with changing EMS requirements, the General Devices GEMS SERIES $\mathbf{2 0 0 0}$ is the FIRST AND ONLY fully integrated, configurable PMC. Utilizing state-of-the-art microprocessor based telecommunications technology, the GEMS SERIES 2000 provides those features you need most: Simplicity, Versatility, and Reliability. Configurable AT ANY TIME to your changing communications environment, whether you rely on cellular telephone, matrix systems, or direct base station control... in the changing ALS world, the GEMS SERIES 2000 is the only logical choice.

\section{Advanced Telecommunications}

* Automatic call handling for cellular, radio, \& landline-no external phone needed

* Call hold and conferencing, speed dialing

* 3 line capability

* Remote base station control
Patient Monitoring Made Easy

* Large 9" ECG display with 15 seconds of ECG data

* 40 MM chart recorder with time/date stamp

* High quality front loading cassette recorder with time/date stamp

* Keyswitch protected tape playback for teaching or review

Simplified Operation

* Functionally grouped controls

* Voice announcement of critical messages

* Backlit color-keyed status messages

* 3 clock/timers

* Instant voice repeat

* User programmable functions

Serviceability for the '90s

* Transtelephonic troubleshooting

* Convection cooled-no fans

* User replaceable boards \& modules

Compatible with existing equipment, desktop or rack mountable, taking up about half the space you'd expect, the GEMS SERIES 2000 PMC will also take up a lot less of your budget!

Call or write for more information and videotape.
GENERAL DEVICES

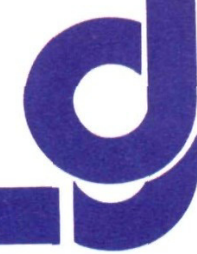

190 Leonia Avenue, Bogota, New Jersey 07603 / 201-343-8135 / FAX 201-343-0655

\section{“Making Ideas Happen in Medical Electronics Since 1979"}


Specialization of Prehospital Emergency Services ShmatovAV, Stazhadze LL, Kostomarova LG, ElkisJS, Chervochkin EN, Vdovina $G$

Improvement in the quality of and the accessibility of high quality emergency medical care to the population is the leading task of the Emergency Medical Care Service. As the Emergency Medical Care Service developed in the past, specialized mobile teams (cardiologic, toxicologic, traumatologic, etc.) were organized and staffed with highly skilled personnel and provided with supplementary equipment. It has become evident, however, that such an organization leads to a number of difficult problems, such as guaranteeing the high specialization of these teams and the appropriate use of the specialized team.

The greatest difficulty is with the dispatch of the appropriate specialized teams to calls. Our study shows that only 60 $62 \%$ of the time is the special team the appropriate one for the final diagnosis. Further, as the population requires more specialized medical care at the prehospital level, the formation of these highly specialized teams becomes much more costly, as the cost of one call of such a team is two to five times the cost of a regular mobile team.

In response to this problem, we have started to organize "polyvalent teams" of intensive therapy staffed with personnel possessing wider knowledge and skills. The Moscow Station of Emergency Care, along with the N.V. Sklifosovosky Research Institute of Emergency Care, has created "teams of intensive therapy." This is done by combining personnel and equipment from the highly specialized teams with those of the ordinary mobile teams. Doctors and feldshers from the regular teams are given special education in order to qualify to serve on the intensive therapy teams.

At present, the emergency medical care in Moscow has 31 functioning intensive therapy teams with broad specialization. Our analyses have shown that, in $91.6 \%$ of cases, the methods of diagnosis, resuscitation, and intensive therapy applied by these teams in the acute situation do not differ by the methods use by the highly specialized teams. These results were confirmed by independent expert evaluations of the quality of care rendered by the highly specialized and intensive therapy teams. Discrepancies in diagnosis were noted in $4.8 \%$ of cases attended by highly specialized teams and $5.3 \%$ of cases attended by the teams of intensive therapy. Thus, it seems that the teams of intensive therapy are much more cost efficient.

\section{The Role of Hepatic Injury in Death Following Multiple Trauma \\ Vladimirova ES, Romanov PA, Evdokimov VN}

Over a one year period (1988), we saw 264 prehospital deaths due to multiple trauma. In $140(53 \%)$ cases, there was associated blunt hepatic trauma. These cases were reviewed retrospectively to clarify the contribution of liver injury to mortality. In order to estimate the severity of liver trauma, 40 post-mortem investigations were carried out with detailed examination of the hepatic vascular system and parenchyma. X-ray contrast investigations were carried out as well. The data were used to categorize the types of hepatic trauma into five classes:

I. Complete rupture of the organ.

II. Central rupture with deep lacerations extending from the hilus along the hepatic veins formation of intraparenchymal cavities.

III. Multiple medium and minor lacerations of both lobes.

IV. Ruptures of peripheral parts of the liver.

V. Subcapsular and intrahepatic hematomas.

Analysis of the 40 cases showed that the injuries were distributed as follows:

\begin{tabular}{|lcc|}
\hline Class & Patients & Percent \\
\cline { 3 - 4 } \cline { 3 - 3 } I & 8 & 20 \\
II & 3 & 8 \\
III & 8 & 20 \\
IV & 18 & 45 \\
V & 3 & 8 \\
& & \\
\hline
\end{tabular}

On an angiogram, patients with type I injury had extensive damage of the major hepatic vessels. Other classes of liver trauma had vascular damage at parenchymal and lobar levels.

Results demonstrate that blunt hepatic trauma plays a leading role in the cause of death in approximately $20 \%$ of patients with lethal traumatic injuries. 


\section{The Logistics of Fluid Resuscitation Planning During Mass Casualty Situations}

Khvatov VB, Oleynik VA

Fluid resuscitation is an effective and necessary therapy in the treatment of most survivors of natural disasters or industrial catastrophes. We have studied the efficiency of fluid resuscitation therapy in survivors after the Armenian earthquake ( 75 patients with crush syndrome), after the catastrophe in Bashkiria (187 burn patients), and in patients with industrial trauma (119 cases with chemical injury, 88 cases with multi-trauma). Seventy-five to $85 \%$ of patients brought to the Institute either were critical or of moderate severity. Therefore, in mass casualties, it seems conservative to assume that all patients admitted to the Institute were in critical condition. Previously, his assumption has been used to calculate the required institutional fluid needs in a mass casualty situation.

On the basis of our investigation and the cost of complex intensive infusion therapy, the optimal ratio of whole blood, its components, blood preparations, and blood substitutes have been calculated (see below).

Anuria from renal failure may complicate these conditions and make fluid resuscitation more difficult. Therefore, removing fluid from the body by hemodiafiltration may be necessary in order to provide effective fluid therapy. The DIC syndrome and secondary immune deficiency may require the use of plasmapheresis, hemostaziotics, and immune correctors.

\begin{tabular}{|c|c|c|c|c|c|c|}
\hline & $\begin{array}{l}\text { Whole } \\
\text { Blood }\end{array}$ & $\begin{array}{l}\text { Blood } \\
\text { Components }\end{array}$ & $\begin{array}{l}\text { Blood } \\
\text { Preparation }\end{array}$ & $\begin{array}{l}\text { Blood } \\
\text { Substitules }\end{array}$ & $\begin{array}{l}\text { Length of } \\
\text { Therapy }\end{array}$ & $\begin{array}{l}\text { Cost } \\
\text { (Rubles) }\end{array}$ \\
\hline Multiple & & & & & & \\
\hline $\begin{array}{l}\text { Trauma } \\
\text { Chemical }\end{array}$ & 1 & 3 & 4 & 15 & 2 days & $350-390$ \\
\hline $\begin{array}{l}\text { Trauma } \\
\text { Burn }\end{array}$ & 1 & 6 & 6 & 79 & 3 day & $90-100 \mathrm{~s}$ \\
\hline $\begin{array}{l}\text { Toxemia } \\
\text { Crush }\end{array}$ & 1 & 12 & 20 & 68 & 10 days & $600-700$ \\
\hline Syndrome & 1 & 10 & 9 & 54 & $\begin{array}{l}\text { 4-5 wks } \\
\text { er Medicine }\end{array}$ & $\begin{array}{l}1200-1500 \\
\text { o Khvatov, et }\end{array}$ \\
\hline
\end{tabular}

\section{Organization of Temporary EMS Systems Dur- ing the Armenian Disaster Teriaev VG, Torosian RR, Gazietov BM, Kizhajkin VS, Saakian ES}

During the 1988 earthquake in Armenia, all treatment and prophylactic centers in Leninekan (except clinic N1) were destroyed and could not admit patients. Under these circumstances, extracted patients initially were brought to the city emergency station and kept on an open air ward on its grounds. Medical staff of the station did everything they could under those conditions to help the injured. Later, as transportation and communication facilities became available, survivors were evacuated to hospitals in neighboring towns.

The establishment of a temporary emergency medical system was the main task in the difficult situation. Research workers of the Disaster Medicine Department of the Sklifosovosky Institute in the Emergency Medicine Service faculty worked in close cooperation with Armenian specialists to organize a workable Emergency Medicine system. The city was divided into ten sections, depending on where the most active rescue work was needed and where the greatest concentration of people was found (such as the Railway Station and Bus Station). In each section, ambulances and passenger buses always were ready to transport patients. Buses were converted into mobile hospitals with fifteen stretchers in each bus. Special radio communication systems were established to communicate with Disaster Relief Headquarters. One-hundred-fifty to two-hundred patients received care in each mobile hospital each day.

With this temporary EMS system, we were able to deliver urgent medical care to casualties of the earthquake. The temporary hospitals also gave us a chance to lighten the workload on other medical teams and allow them to reopen hospitals and outpatient departments as they again became usable. 


\section{Pedi-Pac. \\ When Immobilizing a Child, \\ You Need the Best Fit-Fast.}

Don't waste precious time at the scene of a pediatric emergency trying to modify equipment meant for adults. The new Ferno Pedi-Pac provides proper pediatric stabilization both at the scene and during transport.

The unique color-coded strap system is unsurpassed in quickness of application and in allowing direct access to a child's body for monitoring vital cardiac and respiratory status as well as intraosseous infusion sites.

The Ferno Pedi-Pac's adjustable fourpoint harness system uses child safety seat hardware to ensure maximum patient safety during transport. And the Pedi-Pac conveniently stores under a squad bench or in an exterior compartment. So grab the Ferno Pedi-Pac on your way to a pediatric call. It's the extra assurance you need when treating a child.

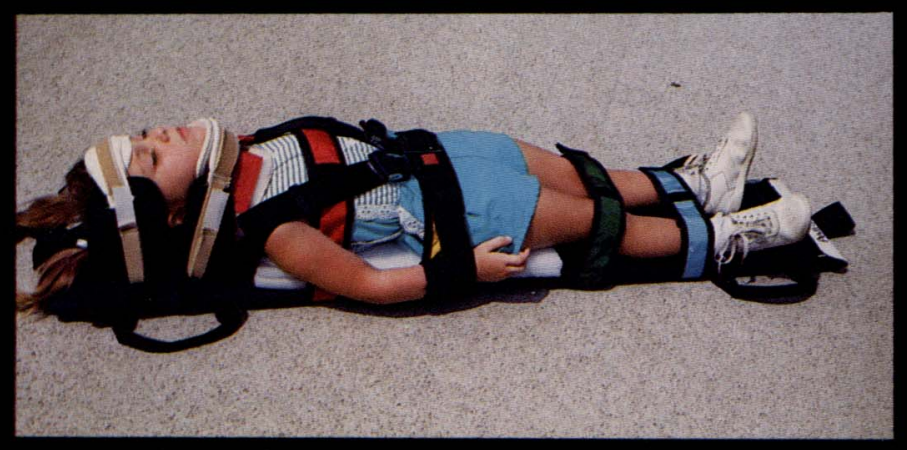

